\title{
Analysis of equations of state for polymers
}

\author{
Erlí José Padilha Júnior ${ }^{1}$, Rafael de Pelegrini Soares ${ }^{1}$ and Nilo Sérgio Medeiros Cardozo ${ }^{1 *}$ \\ 'Departamento de Engenharia Química - DEQUI, Universidade do Rio Grande do Sul - UFRGS, \\ Porto Alegre, $R S$, Brazil \\ *nilo@enq.ufrgs.br
}

\begin{abstract}
In the literature there are several studies comparing the accuracy of various models in describing the PvT behavior of polymers. However, most of these studies do not provide information about the quality of the estimated parameters or the sensitivity of the prediction of thermodynamic properties to the parameters of the equations. Furthermore, there are few studies exploring the prediction of thermal expansion and compression coefficients. Based on these observations, the objective of this study is to deepen the analysis of Tait, HH (Hartmann-Haque), MCM (modified cell model) and SHT (simplified hole theory) equations of state in predicting the PvT behavior of polymers, for both molten and solid states. The results showed that all equations of state provide an adequate description of the PvT behavior in the molten state, with low standard deviations in the estimation of parameters, adequate sensitivity of their parameters and plausible prediction of specific volume, thermal expansion and isothermal compression coefficients. In the solid state the Tait equation exhibited similar performance to the molten state, while HH showed satisfactory results for amorphous polymers and difficulty in adjusting the PvT curve for semicrystalline polymers.
\end{abstract}

Keywords: equation of state, PvT behavior, polymer.

\section{Introduction}

The study of the thermodynamic behavior of polymers is essential to analyze the physical transformations that occur during processing, e.g. injection molding or extrusion, and to predict the properties of the final products. Polymers in melt state or in solution can be represented correctly by an equation of state (EoS) because these can be considered equilibrium states for polymers. Conversely, the solid state is at least one quasi-equilibrium state, because the properties depend on the conditions of solidification, as the cooling rate and pressure, which difficults their description by means of $\operatorname{EoS}^{[1]}$.

Numerous equations of state have been developed to describe the PvT (pressure-volume-temperature) behavior of polymers. In literature, there are several studies comparing the fitting accuracy of various models for PvT data of polymers ${ }^{[1-7]}$. These studies are focused mainly in the analysis of the fitting accuracy of the specific volume in the molten state, employing usually the method of least square ${ }^{[2,3,6,8-20]}$ for the parameter estimation step. They showed that the theoretical equations based on cell-and-hole models and the Tait and the Hartmann-Haque $(\mathrm{HH})$ empirical equations are those which provide more accurate fitting of the experimental data.

On the other hand, little information is available in the literature on at least two important aspects that are essential for the use of the referred equations in process simulation: quality of the estimated parameters as a function of the model employed and fitting accuracy of the models for thermal expansion and isothermal compression coefficients.

The isobaric thermal expansion coefficient $(\beta)$ and isothermal compressibility $(\kappa)$ are defined by:

$$
\beta=\frac{1}{v}\left(\frac{\partial v}{\partial T}\right)_{P}
$$

$$
\kappa=-\frac{1}{v}\left(\frac{\partial v}{\partial P}\right)_{T}
$$

where the negative sign indicates the volume decrease with pressure increase ${ }^{[21]}$.

These coefficients are important for the simulation of polymer processing operations, because they are present in the governing equation of energy conservation. However, to the best of our knowledge, the only studies on their prediction from EoS are those of Utracki ${ }^{[22,23]}$, in which the prediction of thermal expansivity and compressibility by hole models is analyzed.

Based on these observations, the objective of this study is to deepen the analysis of Tait, HH, MCM (modified cell model) and SHT (simplified hole theory) equations of state in prediction of PvT behavior of polymers, in both molten and solid physical states. The EoS were analyzed with respect to: (i) quality in the estimation of its parameters by the method of least squares, (ii) sensitivity of their predictions to each of its parameters, (iii) quality of the prediction of the specific volume, and (iv) quality of the prediction of isobaric thermal expansion coefficient and isothermal compressibility.

\section{Equations of State Analyzed}

\subsection{Tait equation of state}

This equation is purely empirical, and was originally proposed for water. Presently, through various modifications, it is applied to a wide variety of substances, being possibly one of the equations of state most used to model the PvT behavior of polymers ${ }^{[3]}$. For some authors, it is not a true equation of state, but an isothermal compressibility model 
(i.e., a volume-pressure relationship). Tait equation can be written as ${ }^{[3]}$.

$$
v(T, P)=v_{o}(T)\left[1-C \ln \left(1+\frac{P}{B(T)}\right)\right]+v_{t}(T, P)
$$

where for polymers in the molten state, i.e., above the liquid-solid transition temperature:

$$
\begin{aligned}
& v_{o}=b_{1 m}+b_{2 m}\left(T-b_{5}\right) \\
& B(T)=b_{3 m} \exp \left[-b_{4 m}\left(T-b_{5}\right)\right] \\
& v_{t}(T, P)=0
\end{aligned}
$$

and for polymers in solid state, i.e., below the liquid-solid transition temperature

$$
\begin{aligned}
& v_{o}=b_{1 s}+b_{2 s}\left(T-b_{5}\right) \\
& B(T)=b_{3 s} \exp \left[-b_{4 s}\left(T-b_{5}\right)\right] \\
& v_{t}(T, P)=b_{7} \exp \left\{\left[b_{8}\left(T-b_{5}\right)\right]-\left(b_{9} P\right)\right\}
\end{aligned}
$$

The liquid-solid transition temperature, which is the glass transition temperature for amorphous polymers and the melting or crystallization temperature for semicrystalline polymers, can be calculated by

$$
T_{t}(P)=b_{5}+b_{6} P
$$

In these equations, $v$ is the specific volume of the polymeric material; the coefficient $C$ is a constant equal to $0.0894 ; v_{o}$ is the specific volume at zero pressure; $v_{t}$ is the specific volume corresponding to crystalline phase; $B$ is the sensitivity to pressure of material; $b_{1}$ at $b_{9}$ are parameters of model, obtained by fitting of PvT diagram. The parameters $b_{1 m}$ to $b_{4 m}$ and $b_{1 s}$ to $b_{4 s}$ describe the dependence on pressure and temperature in the molten and the solid state, respectively; $b_{5}$ and $b_{6}$ are parameters that describe the change of transition temperature with pressure; $b_{7}$ to $b_{9}$ are particular parameters of semicrystalline polymers that describe the form of the state transition ${ }^{[24]}$.

\subsection{HH equation of state}

Hartmann and Haque ${ }^{[10]}$ developed an empirical equation of state combining the thermal pressure function of Pastine and Warfield, the zero-pressure isobar presented by Somcynsky and Simha, and the empirical dependence of volume with the thermal pressure. HH EoS describes the PvT behavior of polymers in the molten and solid states. It is given by:

$$
\tilde{P} \tilde{v}^{5}=\tilde{T}^{3 / 2}-\ln \tilde{v}
$$

where the dimensionless variables $\tilde{P}, \tilde{v}$ and $\tilde{T}$ for molten polymers are defined as:

$$
\tilde{P}=\frac{P}{B_{0 m}} ; \quad \tilde{v}=\frac{v}{v_{0 m}} ; \tilde{T}=\frac{T}{T_{0 m}}
$$

and for solid polymers as:

$$
\tilde{P}=\frac{P}{B_{0 s}} ; \tilde{v}=\frac{v}{v_{0 s}} ; \tilde{T}=\frac{T}{T_{0 s}}
$$

where $B_{0}, v_{0}$ and $T_{0}$ are the characteristic parameters. $T_{0}$ and $v_{0}$ are defined as temperature and specific volume, respectively, extrapolated to zero pressure, while $B_{0}$ is identified as the isothermal bulk modulus extrapolated to zero temperature and pressure.

\subsection{MCM equation of state}

The modified cell model equation of state was developed by Dee and Walsh ${ }^{[2]}$, starting from the formalism presented by Prigogine et al. ${ }^{[25]}$. In the cell model, the compressibility and thermal expansion of the structure are explained only by changes in the cell volume. Dee and Walsh ${ }^{[2]}$ introduced a numerical factor that scales the hard-core cell volume in the free volume term, disconnecting the theory from the specific geometry. This factor, $q$, was found to be constant for numerous polymers and equal to about 1.07. MCM EoS can be written as:

$$
\frac{\tilde{P} \tilde{v}}{\tilde{T}}=\frac{\tilde{v}^{1 / 3}}{\tilde{v}^{1 / 3}-0.8909 q}-\frac{2}{\tilde{T}}\left(\frac{1.2045}{\tilde{v}^{2}}-\frac{1.011}{\tilde{v}^{4}}\right)
$$

The reduced parameters $\tilde{P}, \tilde{v}$ and $\tilde{T}$ are defined as:

$$
\widetilde{P}=\frac{P}{P^{*}} ; \tilde{v}=\frac{v}{v^{*}} ; \tilde{T}=\frac{T}{T^{*}}
$$

where $P^{*}, v^{*}$ and $T^{*}$ are characteristic parameters.

\subsection{SHT equation of state}

The hole theory introduces empty cells in the cell model ${ }^{[26]}$, based on the concept that the thermal expansion of liquid is mainly due to holes $(h)$, i.e., the empty cells, while volume changes of the cells are also allowed. Zhong et al. ${ }^{[27]}$ simplified the hole theory through the use of an exponential function to the fraction of occupied cells. SHT EoS is derived as:

$$
\frac{\tilde{P} \tilde{v}}{\tilde{T}}=\frac{(y \tilde{v})^{1 / 3}}{(y \tilde{v})^{1 / 3}-0.9165 y}+\frac{2 y}{\tilde{T}(y \tilde{v})^{2}}\left(\frac{1.1394}{(y \tilde{v})^{2}}-1.5317\right) \text { (12) }
$$

where $\tilde{P}, \tilde{v}$ and $\tilde{T}$ are reduced parameters defined by Equation 11, $y$ is the fraction of occupied cells, being defined by:

$$
y=1-e^{-0.52 / \tilde{T}}
$$

\section{Methodology}

The experimental PvT data used in this work were taken from the literature ${ }^{[7,21,28-32]}$ as shown in Table 1. For each polymer, the available data were subdivided in two sets: one used for parameter estimation (DATA1) and other for validation (DATA2). The construction of these subsets was based on random selection of points.

Differently from specific volume data, the isobaric thermal expansion and isothermal compression coefficients are hard to obtain experimentally. Thus, the EoS were only qualitatively analyzed with relation to the prediction of these 


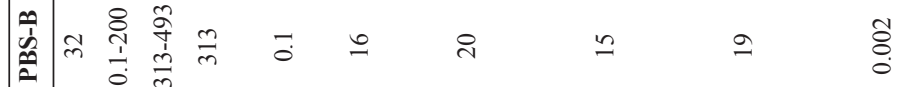

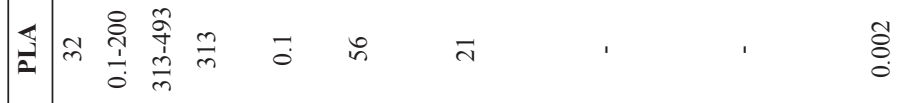

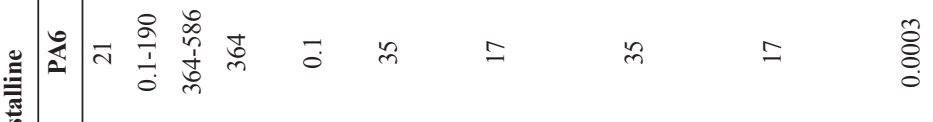

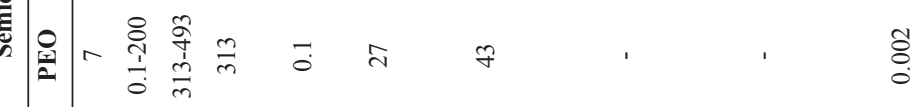

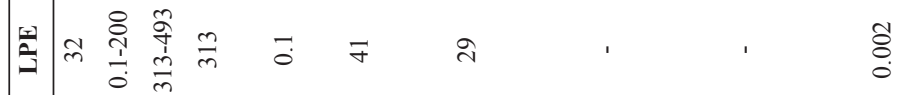

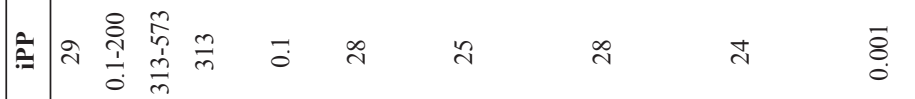

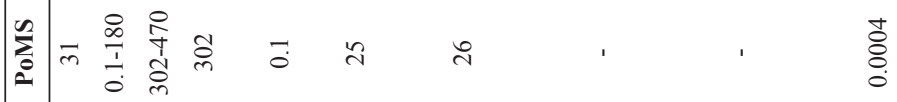

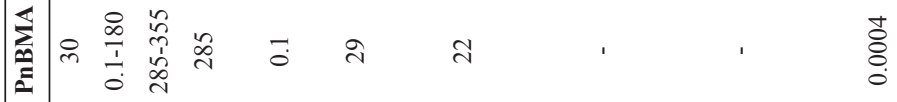

$$
\begin{aligned}
& \text { • }
\end{aligned}
$$

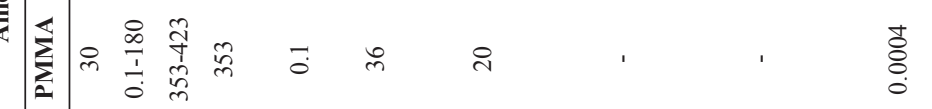

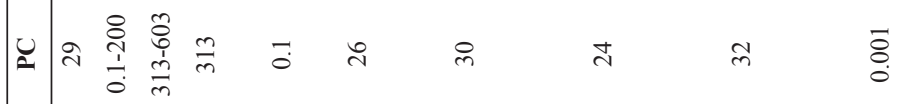

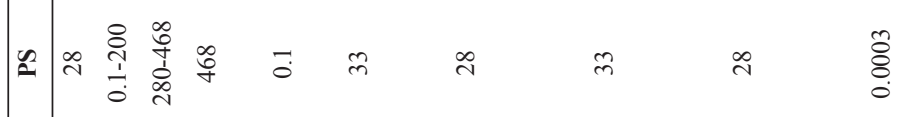


coefficients, taking as basis of comparison their theoretically expected behavior. The estimation of parameters was conducted by the least squares method, using the lsqnonlin function already implemented in MatLab ${ }^{\circledR}$ software, with the following objective function $(F O b j)$ :

$$
F O b j=\sum_{i=1}^{n}\left(\hat{v}_{i}-v_{i}\right)^{2}
$$

where $\left(\hat{v}_{i}-v_{i}\right)$ is the residual between predicted $\left(\hat{v}_{i}\right)$ and experimental $\left(v_{i}\right)$ values and $n$ is the number of points considered.

The parameters of the equations of state were estimated simultaneously, as suggested by Hartmann and Haque ${ }^{[10]}$. For the Tait EoS, firstly, $b_{5}$ and $b_{6}$ were estimated from data of transition temperature at different pressures. The melt parameters $\left(b_{1 m}, b_{2 m}, b_{3 m}\right.$ and $\left.b_{4 m}\right)$ and solid parameters $\left(b_{1 s}, b_{2 s}, b_{3 s}, b_{4 s}, b_{7}, b_{8}\right.$ and $\left.b_{9}\right)$ were estimated separately from data corresponding to the respective states ${ }^{[33]}$. Likewise, for $\mathrm{HH} \mathrm{EoS}$, the experimental data were divided into two states: molten and solid state. The parameters of the MCM and SHT EoS were estimated only with molten state data.

The quality of the estimated parameters for each model was analyzed in terms of their covariance matrix $\left(V_{\alpha}\right)$, evaluated using a routine developed in MatLab ${ }^{\circledR}$, according the following expression ${ }^{[34]}$ :

$$
V_{\alpha}=H_{\alpha}^{-1} G_{\alpha} \sigma_{y}^{2} G_{\alpha}^{T}\left(H_{\alpha}^{-1}\right)^{T}
$$

where $\sigma_{y}^{2}$ is the experimental data variance, $H_{\alpha}$ is the Hessian matrix of $F O b j$, and $G_{\alpha}$ is the matrix that represents the derivative of the gradient of $F O b j$ with relation to the experimental values $v_{i}$.

The normalized parameter sensitivity matrix was used to evaluate the sensitivity of the predictions of the considered EoS to parameter variations. The coefficients of this matrix are given by:

$$
S_{i j}^{*}=\frac{\partial \hat{v}_{i}}{\partial a_{j}}\left(\frac{a_{j}}{\hat{v}_{i}}\right)
$$

where $a_{j}$ is the parameter of the equation analyzed. These coefficients were calculated using a MatLab ${ }^{\circledR}$ function, according to the following central-difference approximation:

$$
S_{i j}^{*}=\frac{v_{i}\left(\alpha_{j}+h\right)-v_{i}\left(\alpha_{j}-h\right)}{2 h}\left(\frac{\alpha_{j}}{v_{i}}\right)
$$

with $h$ equal to $10^{-4}$. In this way, the parameter sensitivity of the specific volume predictions was analyzed in a wide temperature range, at different pressures, for polycarbonate and linear polyethylene.

To appraise the fit and prediction quality of each model, the mean relative deviation (MRD) and the regression coefficient $\left(R^{2}\right)$ were calculated:

$$
\begin{aligned}
& M R D=\frac{100}{n} \sum_{i=1}^{n} \frac{\left|v_{i}-\hat{v}_{i}\right|}{v_{i}} \\
& R^{2}=1-\frac{\sum_{i=1}^{n}\left(v_{i}-\hat{v}_{i}\right)^{2}}{\sum_{i=1}^{n}\left(v_{i}-\bar{v}_{i}\right)^{2}}
\end{aligned}
$$

where $\bar{v}_{i}$ is the arithmetic mean of experimental specific volumes.

Additionally, F-tests were performed to assess the suitability of the considered models. The value of $F_{0}$ used in the comparison with the critical value of $\mathrm{F}\left(F_{c}=\mathrm{F}\right.$ distribution value corresponding to $95 \%$ confidence) was defined as the ratio between the model $\left(\sigma_{e o s}^{2}\right)$ and the experimental $\left(\sigma_{\text {exp }}^{2}\right.$ ) variances, according to the following expression:

$$
F_{0}=\frac{\sigma_{\operatorname{eos}}^{2}}{\sigma_{\exp }^{2}}=\frac{\frac{\sum_{i}^{n}\left(v_{i}-\hat{v}_{i}\right)^{2}}{n-n p}}{\sigma_{\exp }^{2}}
$$

where $n p$ is the number of estimated parameters. The experimental variances are shown in Table 1 .

\section{Results and Discussion}

\subsection{Fitting and prediction of specific volume}

As mentioned previously, the comparison of the EoS under analysis with relation to the fitting of specific volume data has already been extensively studied by other authors ${ }^{[2,3,6,8-20]}$. Therefore, in the present work, the analysis corresponding to the fitting stage will be focused only in the quality of the estimated parameters, aspect for which there is little information available in the literature.

The values of parameters estimated from data set DATA1 and their respective standard deviations are presented in Tables 2 and 3, for the amorphous and semicrystalline polymers, respectively. The low values of the standard deviations indicate that the fitting were adequate. The parameters of equations of state showed a higher standard deviation for semicrystalline polymers, in both physical states. The fitting of Tait and $\mathrm{HH}$ EoS were better in molten state, both to amorphous and semicrystalline polymers. In general, Tait equation exhibited the lowest values of standard deviations (below 2\%) except for the parameter $b_{6}$ in the cases of the polymers iPP and PLA, for which the linear dependence between transition temperature and pressure described by Equation 6 is not obeyed. For all equations of state, the greatest deviations were found for the parameters related to pressure, what can be explained by the wide range of pressure analyzed.

For the evaluation of the prediction capability of the studied models, calculations of specific volume for the conditions corresponding to each experimental data of data set DATA2 were performed using the values of parameters estimated with data set DATA1 (Tables 2 and 3 ). The values of $F_{0}, \mathrm{MRD}$ and $R^{2}$ obtained are presented in Table 4, together with the respective values of $F_{c}$ used in the F-test to $95 \%$ confidence. As can be seen in Table 4, all the four EoS provided predictions not significantly different from the experimental data $\left(F_{0}<F_{c}\right)$, showing their adequacy in the prediction of the PvT behavior of the considered polymers. It is observed that Tait equation exhibited the lowest relative deviation module mean and the highest regression coefficient in most cases. However, the other equations of state studied also presented satisfactory results, with values close to those obtained with Tait EoS. The only exception was in the prediction of specific volume of semicrystalline 
Table 2. Estimated parameters $\left(a_{i}\right)$ and percentage standard deviation $\left(\sigma_{a i}\right)$ for amorphous polymers.

\begin{tabular}{|c|c|c|c|c|c|c|c|c|c|c|c|c|c|c|}
\hline \multirow{2}{*}{ EoS } & \multirow{2}{*}{ Parameter } & \multicolumn{2}{|c|}{ PS } & \multicolumn{2}{|c|}{ PC } & \multicolumn{2}{|c|}{ PMMA } & \multicolumn{2}{|c|}{ РСНMA } & \multicolumn{2}{|c|}{ PnBMA } & \multicolumn{2}{|c|}{ PoMS } & \multirow{2}{*}{$\begin{array}{c}\text { Mean } \\
\sigma_{a i}(\%)\end{array}$} \\
\hline & & $a_{i}$ & $\sigma_{a i}(\%)$ & $a_{i}$ & $\sigma_{a i}(\%)$ & $a_{i}$ & $\sigma_{a i}(\%)$ & $a_{i}$ & $\sigma_{a i}(\%)$ & $a_{i}$ & $\sigma_{a i}(\%)$ & $a_{i}$ & $\sigma_{a i}(\%)$ & \\
\hline \multirow[t]{10}{*}{ Tait } & $b_{1 m}\left(\mathrm{~cm}^{3} / \mathrm{g}\right)$ & 0.9767 & 0.0015 & 0.8590 & 0.0025 & 0.8603 & 0.0024 & 0.9318 & 0.0017 & 0.9469 & 0.0014 & 1.0046 & 0.0013 & 0.0018 \\
\hline & $b_{2 m}\left(\mathrm{~cm}^{3} / \mathrm{gK}\right)$ & 0.000506 & 0.0461 & 0.000553 & 0.0392 & 0.000511 & 0.1042 & 0.000596 & 0.0477 & 0.000628 & 0.0532 & 0.000547 & 0.0492 & 0.0566 \\
\hline & $b_{3 m}(M P a)$ & 154.65 & 0.0672 & 151.39 & 0.1062 & 277.56 & 0.1512 & 161.98 & 0.0629 & 192.89 & 0.0998 & 184.57 & 0.0882 & 0.0959 \\
\hline & $b_{4 m}(1 / K)$ & 0.0030 & 0.2749 & 0.0034 & 0.2218 & 0.0075 & 0.6696 & 0.0052 & 0.1845 & 0.0047 & 0.4290 & 0.0062 & 0.2388 & 0.3364 \\
\hline & $b_{1 s}\left(\mathrm{~cm}^{3} / \mathrm{g}\right)$ & 0.9748 & 0.0015 & 0.8575 & 0.0035 & 0.8625 & 0.0007 & 0.9303 & 0.0014 & 0.9479 & 0.0011 & 1.0045 & 0.0018 & 0.0017 \\
\hline & $b_{2 s}\left(\mathrm{~cm}^{3} / \mathrm{gK}\right)$ & 0.000213 & 0.1116 & 0.000192 & 0.2435 & 0.000275 & 0.1665 & 0.000248 & 0.1118 & 0.000376 & 0.3084 & 0.000232 & 0.0996 & 0.1736 \\
\hline & $b_{3 s}(M P a)$ & 275.87 & 0.0645 & 249.21 & 0.1005 & 257.75 & 0.0303 & 255.61 & 0.0486 & 223.53 & 0.0373 & 276.20 & 0.0649 & 0.0577 \\
\hline & $b_{4 s}(1 / K)$ & 0.0018 & 0.6080 & 0.0021 & 0.7384 & 0.0045 & 0.3877 & 0.0038 & 0.3082 & 0.0036 & 0.8858 & 0.00067 & 1.2603 & 0.6981 \\
\hline & $b_{5}(K)$ & 370.86 & 0.0026 & 417.06 & 0.0059 & 375.30 & 0.0034 & 383.84 & 0.0030 & 296.66 & 0.0039 & 401.21 & 0.0028 & 0.0036 \\
\hline & $b_{6}(K / M P a)$ & 0.3924 & 0.0211 & 0.2687 & 0.0885 & 0.3485 & 0.0692 & 0.2665 & 0.0441 & 0.2225 & 0.0528 & 0.3361 & 0.0350 & 0.0518 \\
\hline \multirow[t]{6}{*}{$\mathrm{HH}$} & $B_{0 m}(\mathrm{MPa})$ & 2953.3 & 1.3157 & 3470.2 & 2.6453 & 5238.2 & 5.0184 & 3115.0 & 1.3573 & 3654.1 & 2.5917 & 3154.5 & 2.1292 & 2.5096 \\
\hline & $v_{0 m}\left(\mathrm{~cm}^{3} / \mathrm{g}\right)$ & 0.8753 & 0.6226 & 0.7413 & 1.3425 & 0.7570 & 0.7592 & 0.8192 & 0.7058 & 0.8431 & 0.6388 & 0.8917 & 0.6503 & 0.7865 \\
\hline & $T_{0 m}(\mathrm{~K})$ & 1602.1 & 0.2884 & 1471.8 & 0.6255 & 1464.9 & 0.7126 & 1471.8 & 0.3327 & 1256.7 & 0.4040 & 1631.2 & 0.3724 & 0.4559 \\
\hline & $B_{0 s}(\mathrm{MPa})$ & 4278.5 & 3.6067 & 3858.2 & 7.8331 & 3867.7 & 3.2444 & 4172.8 & 3.7264 & 3499.0 & 3.3230 & 4251.8 & 4.6353 & 4.3948 \\
\hline & $v_{0 s}\left(\mathrm{~cm}^{3} / \mathrm{g}\right)$ & 0.9218 & 0.5102 & 0.8107 & 1.4375 & 0.8158 & 0.5568 & 0.8785 & 0.6056 & 0.8891 & 0.7577 & 0.9399 & 0.6413 & 0.7515 \\
\hline & $T_{0 s}(\mathrm{~K})$ & 2552.0 & 0.4872 & 2914.7 & 1.3898 & 2592.6 & 0.4136 & 2656.6 & 0.5196 & 1863.6 & 0.4846 & 2453.5 & 0.7396 & 0.6724 \\
\hline \multirow[t]{3}{*}{ MCM } & $P^{*}(M P a)$ & 532.04 & 0.4534 & 707.66 & 0.9018 & 1017.5 & 2.1312 & 594.83 & 0.8393 & 656.45 & 0.6733 & 616.17 & 0.9196 & 0.9864 \\
\hline & $v^{*}\left(\mathrm{~cm}^{3} / \mathrm{g}\right)$ & 0.8690 & 0.0822 & 0.7357 & 0.1447 & 0.7463 & 0.2813 & 0.8101 & 0.1353 & 0.8392 & 0.1177 & 0.8745 & 0.1612 & 0.1537 \\
\hline & $T^{*}(K)$ & 6933.9 & 0.3985 & 6441.5 & 0.5280 & 6178.8 & 1.1607 & 6298.7 & 0.5389 & 5427.0 & 0.5621 & 6704.6 & 0.6911 & 0.6466 \\
\hline \multirow[t]{3}{*}{ SHT } & $P^{*}(M P a)$ & 420.57 & 1.0068 & 675.78 & 2.1852 & 887.13 & 6.4028 & 518.74 & 2.1551 & 506.85 & 1.3689 & 577.23 & 4.3201 & 2.9065 \\
\hline & $v^{*}\left(\mathrm{~cm}^{3} / \mathrm{g}\right)$ & 0.9242 & 0.1769 & 0.7620 & 0.3835 & 0.7798 & 0.8736 & 0.8491 & 0.3381 & 0.8937 & 0.2329 & 0.9032 & 0.7175 & 0.4538 \\
\hline & $T^{*}(K)$ & 4009.2 & 0.8431 & 3353.9 & 1.3560 & 3311.9 & 3.4399 & 3425.4 & 1.3222 & 3168.3 & 1.1022 & 3429.9 & 2.7175 & 1.7968 \\
\hline
\end{tabular}

Table 3. Estimated parameters $\left(a_{i}\right)$ and percentage standard deviation $\left(\sigma_{a i}\right)$ for semicrystalline polymers.

\begin{tabular}{|c|c|c|c|c|c|c|c|c|c|c|c|c|c|c|}
\hline \multirow{2}{*}{ EoS } & \multirow{2}{*}{ Parameter } & \multicolumn{2}{|c|}{ iPP } & \multicolumn{2}{|c|}{ LPE } & \multicolumn{2}{|c|}{ PEO } & \multicolumn{2}{|c|}{ PA6 } & \multicolumn{2}{|c|}{ PLA } & \multicolumn{2}{|c|}{ PBS-B } & \multirow{2}{*}{$\begin{array}{c}\text { Mean } \\
\sigma_{a i}(\%)\end{array}$} \\
\hline & & $a_{i}$ & $\sigma_{a i}(\%)$ & $a_{i}$ & $\sigma_{a i}(\%)$ & $a_{i}$ & $\sigma_{a i}(\%)$ & $a_{i}$ & $\sigma_{a i}(\mathbf{\%})$ & $a_{i}$ & $\sigma_{a i}(\%)$ & $a_{i}$ & $\sigma_{a i}(\%)$ & \\
\hline \multirow[t]{13}{*}{ Tait } & $b_{1 m}\left(\mathrm{~cm}^{3} / \mathrm{g}\right)$ & 1.3082 & 0.0021 & 1.2532 & 0.0022 & 1.2301 & 0.0018 & 1.0002 & 0.0030 & 0.8875 & 0.0043 & 0.8837 & 0.0035 & 0.0028 \\
\hline & $b_{2 m}\left(\mathrm{~cm}^{3} / \mathrm{gK}\right)$ & 0.0010 & 0.0378 & 0.000957 & 0.0509 & 0.000932 & 0.0304 & 0.000659 & 0.0873 & 0.000712 & 0.1455 & 0.000622 & 0.0788 & 0.0718 \\
\hline & $b_{3 m}(M P a)$ & 66.84 & 0.0438 & 93.68 & 0.0769 & 113.12 & 0.0577 & 132.00 & 0.0860 & 100.68 & 0.1041 & 152.55 & 0.1278 & 0.0827 \\
\hline & $b_{4 m}(1 / K)$ & 0.0048 & 0.1116 & 0.0046 & 0.2521 & 0.0044 & 0.1411 & 0.0029 & 0.5355 & 0.0047 & 0.5810 & 0.0040 & 0.4383 & 0.3433 \\
\hline & $b_{1 s}\left(\mathrm{~cm}^{3} / \mathrm{g}\right)$ & 1.1804 & 0.0033 & 1.0669 & 0.0030 & 1.1666 & 0.0975 & 0.9600 & 0.0020 & 0.8553 & 0.0025 & 0.8361 & 0.0109 & 0.0199 \\
\hline & $b_{2 s}\left(\mathrm{~cm}^{3} / \mathrm{gK}\right)$ & 0.000517 & 0.0743 & 0.000453 & 0.1063 & 0.000780 & 1.1831 & 0.000489 & 0.0396 & 0.000372 & 0.0695 & 0.000525 & 0.2850 & 0.2930 \\
\hline & $b_{3 s}(M P a)$ & 110.82 & 0.0765 & 228.35 & 0.0825 & 173.63 & 1.3530 & 125.96 & 0.0496 & 148.00 & 0.0902 & 198.59 & 0.3480 & 0.3333 \\
\hline & $b_{4 s}(1 / K)$ & 0.0064 & 0.1556 & 0.0023 & 0.5972 & 0.0029 & 3.0337 & 0.0078 & 0.0830 & 0.0064 & 0.1984 & 0.0057 & 1.1048 & 0.8621 \\
\hline & $b_{5}(K)$ & 452.86 & 0.0055 & 405.47 & 0.0061 & 365.09 & 0.0068 & 501.95 & 0.0020 & 440.44 & 0.0056 & 385.88 & 0.0064 & 0.0054 \\
\hline & $b_{6}(K / M P a)$ & 0.0057 & 4.1917 & 0.2107 & 0.1129 & 0.2043 & 0.1164 & 0.0835 & 0.1127 & 0.0048 & 4.9477 & 0.1254 & 0.1897 & 1.6119 \\
\hline & $b_{7}\left(\mathrm{~cm}^{3} / \mathrm{g}\right)$ & 0.3644 & 0.2083 & 0.4848 & 0.1569 & 0.0565 & 1.9711 & 0.0406 & 0.0709 & 0.0327 & 0.1187 & 0.0133 & 2.7994 & 0.8876 \\
\hline & $b_{8}(1 / K)$ & 0.1429 & 0.1600 & 0.2893 & 0.1153 & 0.0210 & 1.4194 & 0.0890 & 0.0718 & 0.4684 & 0.2048 & 0.1785 & 1.4186 & 0.5650 \\
\hline & $b_{9}(1 / \mathrm{MPa})$ & 0.1133 & 0.2824 & 0.0762 & 0.1072 & 0.0074 & 0.5776 & 0.0029 & 0.2204 & 0.0081 & 0.2998 & 0.0111 & 1.3604 & 0.4746 \\
\hline \multirow[t]{6}{*}{$\mathrm{HH}$} & $B_{0 m}(\mathrm{MPa})$ & 1877.2 & 0.9060 & 2514.9 & 1.5167 & 2581.2 & 1.3639 & 4330.2 & 2.6157 & 3235.6 & 1.6826 & 3648.7 & 3.1454 & 1.8717 \\
\hline & $v_{0 m}\left(\mathrm{~cm}^{3} / \mathrm{g}\right)$ & 1.0864 & 1.5161 & 1.0496 & 1.4684 & 1.0605 & 1.1865 & 0.8137 & 1.5780 & 0.7196 & 1.8242 & 0.7573 & 1.8053 & 1.5631 \\
\hline & $T_{0 m}(\mathrm{~K})$ & 1370.7 & 0.3162 & 1273.9 & 0.4684 & 1277.8 & 0.4502 & 1437.2 & 0.7388 & 1242.7 & 0.6546 & 1327.6 & 0.8649 & 0.5822 \\
\hline & $B_{0 s}(\mathrm{MPa})$ & 2689.0 & 3.2847 & 5508.9 & & 5242.2 & 2.0723 & 5634.4 & 1.7457 & 4112.4 & 4.1033 & 6393.9 & 9.2255 & 4.3786 \\
\hline & $v_{0 s}\left(\mathrm{~cm}^{3} / \mathrm{g}\right)$ & 1.0241 & 1.4413 & 0.9064 & 1.0336 & 0.9097 & 1.6756 & 0.7828 & 0.5857 & 0.7426 & 1.0285 & 0.6945 & 2.0437 & 1.3014 \\
\hline & $T_{0 s}(\mathrm{~K})$ & 1574.8 & 0.9417 & 1284.6 & 0.9761 & 830.57 & 0.5881 & 1396.3 & 0.3584 & 1576.0 & 0.9510 & 1170.2 & 1.4734 & 0.8815 \\
\hline \multirow[t]{3}{*}{$\mathrm{MCM}$} & $P^{*}(M P a)$ & 406.30 & 1.4660 & 497.88 & 1.7795 & 516.67 & 0.9554 & 882.19 & 1.3540 & 668.30 & 3.7141 & 717.11 & 1.6693 & 1.8231 \\
\hline & $v^{*}\left(\mathrm{~cm}^{3} / \mathrm{g}\right)$ & 1.0656 & 0.1957 & 1.0435 & 0.2740 & 1.0492 & 0.1417 & 0.8110 & 0.1867 & 0.7141 & 0.5219 & 0.7510 & 0.2474 & 0.2612 \\
\hline & $T^{*}(K)$ & 5825.1 & 0.5207 & 5601.7 & 0.8363 & 5521.4 & 0.4740 & 6392.2 & 0.4969 & 5457.8 & 1.3499 & 5774.1 & 0.8529 & 0.7551 \\
\hline \multirow[t]{3}{*}{ SHT } & $P^{*}(M P a)$ & 445.72 & 3.5869 & 509.45 & 4.7145 & 509.45 & 2.4290 & 922.41 & 3.4977 & 714.20 & 9.5570 & 678.21 & 4.2874 & 4.6788 \\
\hline & $v^{*}\left(\mathrm{~cm}^{3} / \mathrm{g}\right)$ & 1.0880 & 0.5217 & 1.0730 & 0.7374 & 1.0836 & 0.3770 & 0.8285 & 0.4958 & 0.7288 & 1.3734 & 0.7783 & 0.6555 & 0.6935 \\
\hline & $T^{*}(K)$ & 2929.4 & 1.3930 & 2864.6 & 2.2278 & 2855.9 & 1.2422 & 3209.4 & 1.3034 & 2737.2 & 3.5220 & 3016.0 & 2.2253 & 1.9856 \\
\hline
\end{tabular}




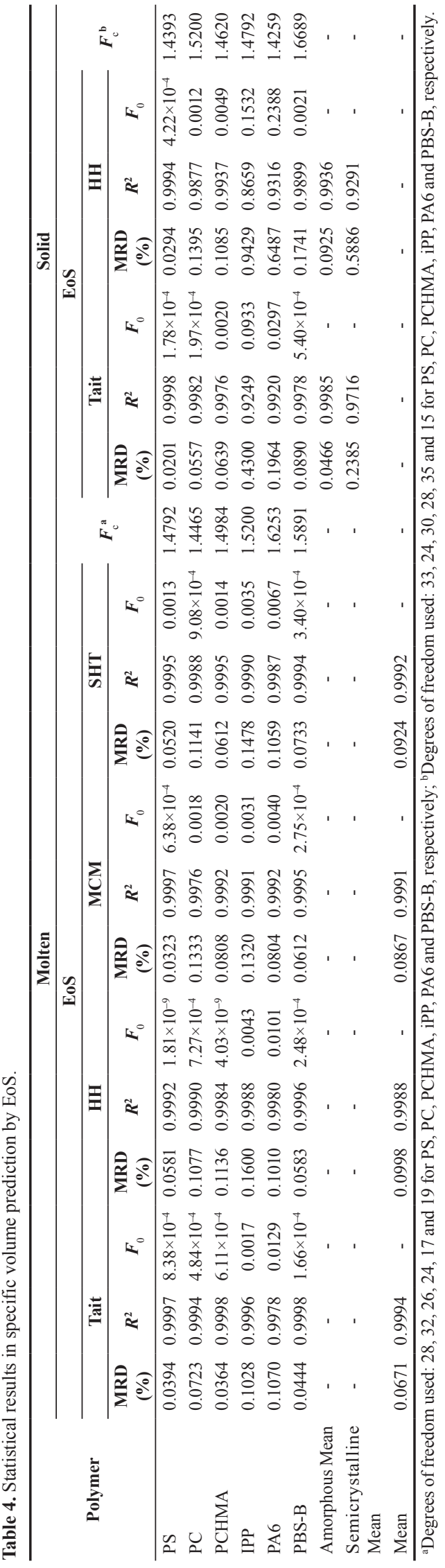


polymers in solid state, where a higher difference between Tait and $\mathrm{HH}$ equations occurred.

Figure 1 shows the residual plots for each equation of state. It is possible to observed that the predominately random nature of the errors distributions for both molten and solid state data, with the predictions of the $\mathrm{HH}$ EoS for molten iPP as only relevant exception. These results support the statement of good suitability of the EoS tested.

As example of the general behavior described in the previous paragraph, Figure 2 shows the variation of MRD with the temperature for an amorphous polymer, PC, and with the pressure and temperature for a semicrystalline one, iPP. It can be seen that the $\mathrm{HH}$ EoS presented a high relative

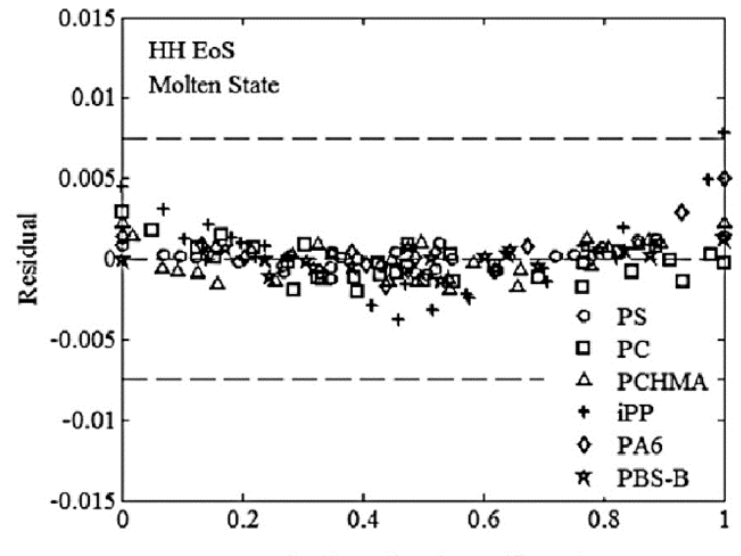

Normalized Predicted Specific Volume

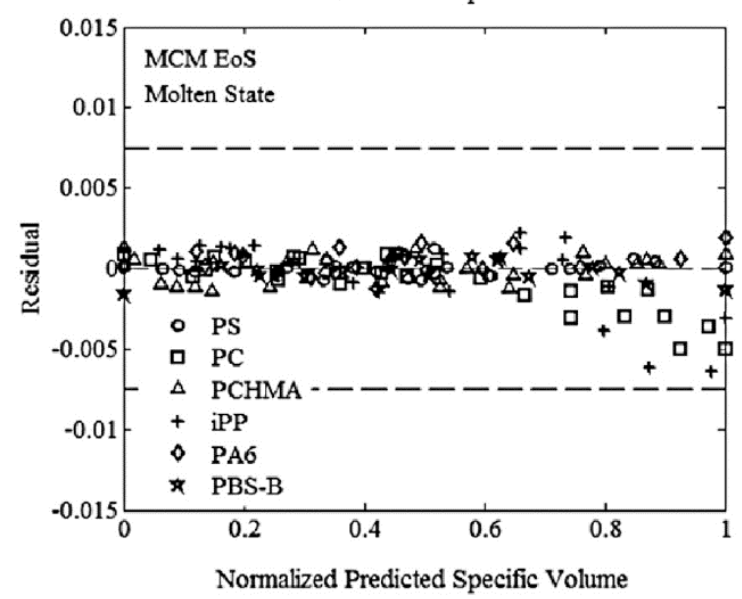

(a)
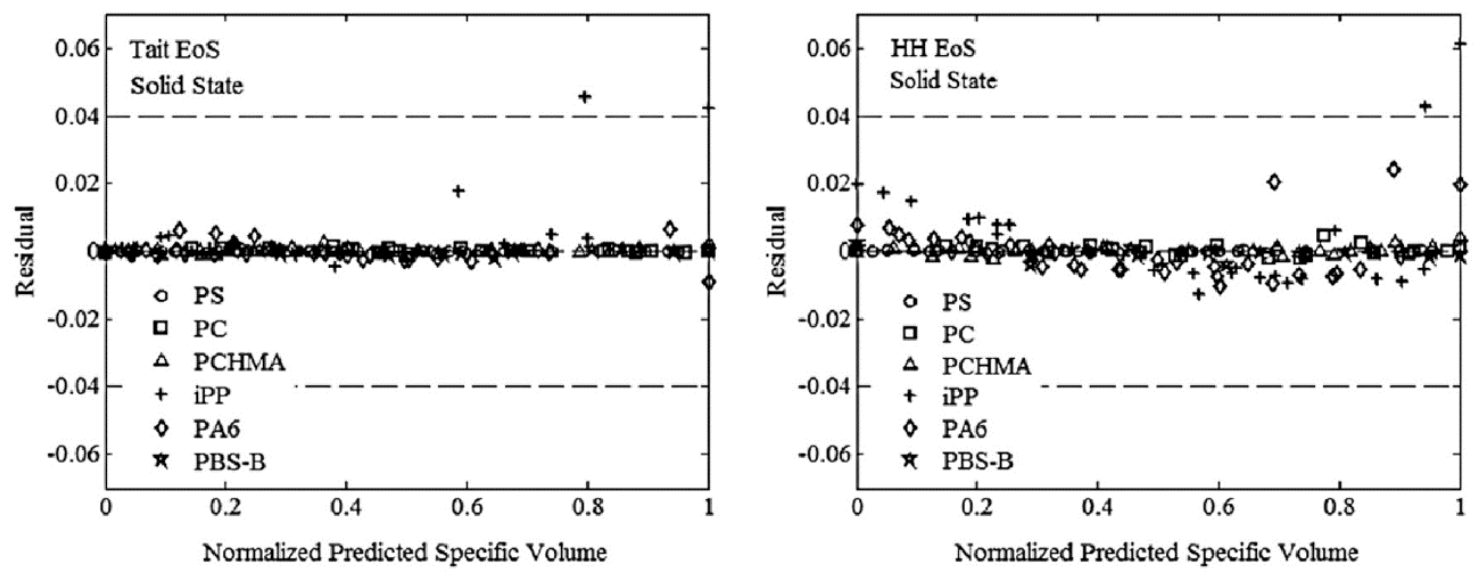

(b)

Figure 1. Residual plots of specific volume predictions for all EoS tested: (a) Molten and (b) Solid state polymers. 


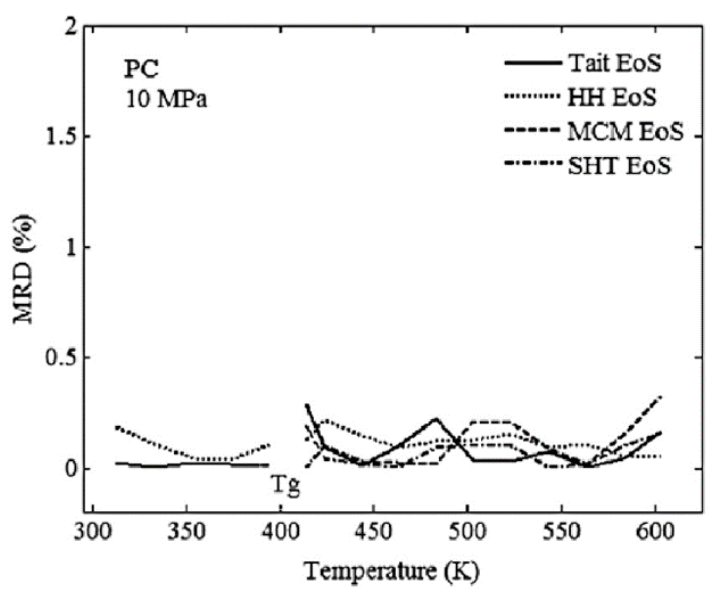

(a)

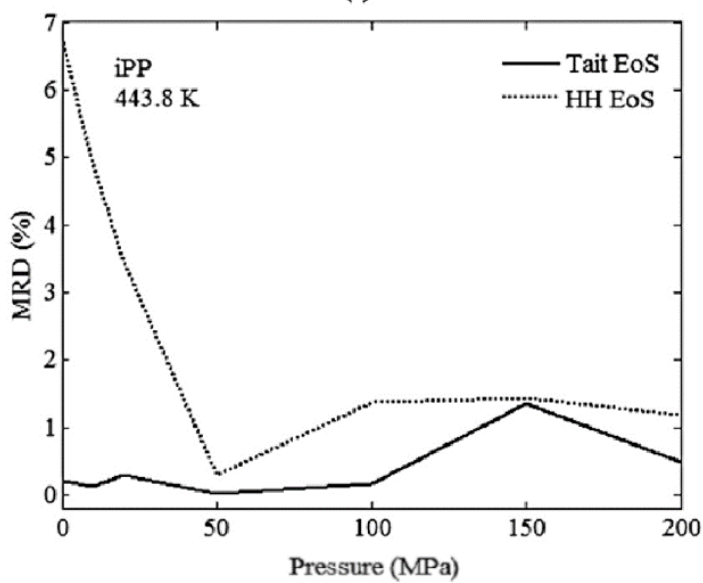

(c)

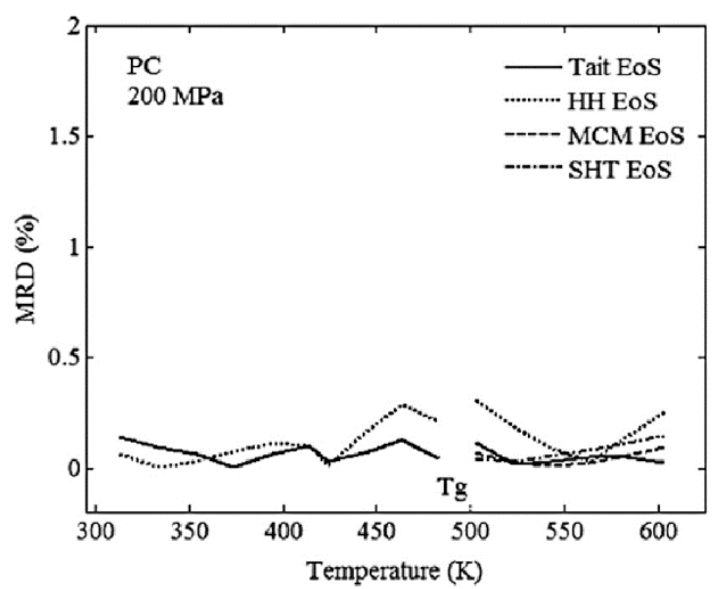

(b)

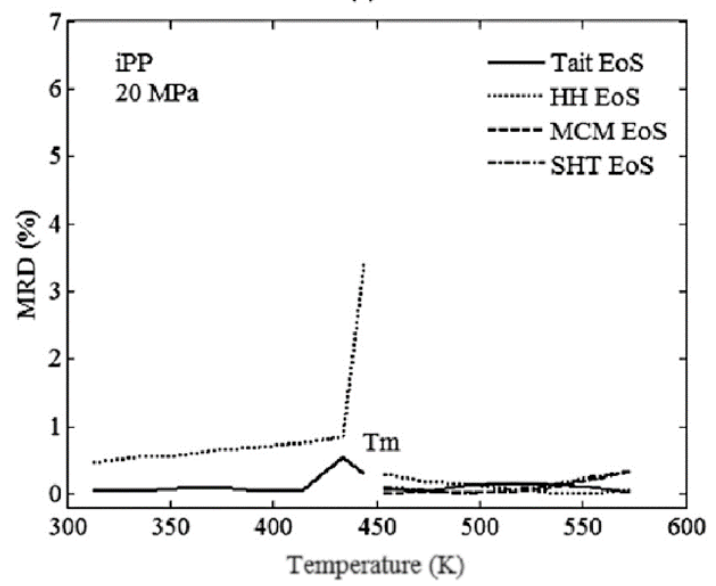

(d)

Figure 2. MRD (\%) in specific volume prediction: (a) PC in $10 \mathrm{MPa}$, (b) PC in $200 \mathrm{MPa}$, (c) iPP in $443.8 \mathrm{~K}$ and (d) iPP in $20 \mathrm{MPa}$.

deviation in solid state, especially at low pressures near the transition temperature (Figures $2 \mathrm{c}$ and $2 \mathrm{~d}$ ).

\subsection{Sensitivity analysis}

The sensitivity of the prediction of specific volume with relation to each parameter of $\mathrm{HH}, \mathrm{MCM}$ and SHT EOS is shown in Figure 3. The sensitivity of parameters showed similar behavior for all these EoS, both to amorphous and semicrystalline polymers. Besides the highest sensitivity corresponds to the volume related parameters, the sensitivity to each parameter was nearly constant in the whole ranges of pressure and temperature analyzed.

For the Tait EoS, the behavior of the sensitivity to the parameters was somewhat different, as shown in Figure 4. The sensitivity to the parameters $b_{1}$ and $b_{2}$ varied continuous and complementarily with the increase of the temperature (Figures $4 \mathrm{~b}$ and $4 \mathrm{c}$ ), with increase of the sensitivity to $b_{1}$ and decrease of the sensitivity to $b_{2}$. Moreover, it is perceived that there was an abrupt change in the sensitivity of the parameters of Tait EoS near the transition temperature of linear polyethylene in the solid state. The sensitivities of parameters $b_{1 s}$ and of term $v_{t}\left(b_{7}, b_{8}\right.$ and $\left.b_{9}\right)$ of Tait equation were modified near the transition region. It is found that there is a correlation between the sensitivities to the parameters $b_{1 s}$ and $b_{7}$, both related to the specific volume. All parameters of the $v_{t}$ term $\left(b_{7}, b_{8}\right.$ and $\left.b_{9}\right)$ reveal sensitivity close to the transition regions, stating that they are within linked in modeling this region. Thus, this transition region has fundamental importance for the estimation of the parameters of the Tait EoS.

\subsection{Isobaric thermal expansion and isothermal compression coefficients prediction analysis}

Figure 5 shows the isobaric thermal expansivity calculated from the PC, PoMS, iPP and PLA by equations of state. It is observed that all the EoS predict similar values of this coefficient and are in qualitative agreement with the theory in the sense that the thermal expansion coefficient of a polymer melt is always greater than that of the corresponding amorphous and semicrystalline solid $^{[35,36]}$. However, Tait EoS, unlike the other equations, predicts a reduction of this coefficient with the increase of the temperature, contrarily to theoretical expectations ${ }^{[35]}$, revealing a limitation of the model. Moreover, in the case of semicrystalline polymers, Tait equation of state presented an abrupt increase in thermal expansion coefficient in the 
crystalline transition region. This occurs because Tait EoS describes satisfactorily sudden change in specific volume due to destruction/growth of crystallites, which does not happen with the $\mathrm{HH}$ equation. The theoretical equations of state, MCM and SHT displayed the same curve shape.

Figure 6 shows the isothermal compressibility predicted from the PC, PoMS, iPP and PLA by equations of state.
It appears that the equations predict values near. The curves exposed by EoS are consistent with the theory ${ }^{[35,36]}$, coefficient gradually increases with temperature and decreases with pressure. Again, as in the case of predicting thermal expansivity, Tait equation of state exhibited an abrupt reduction of isothermal compressibility in the crystalline transition region.

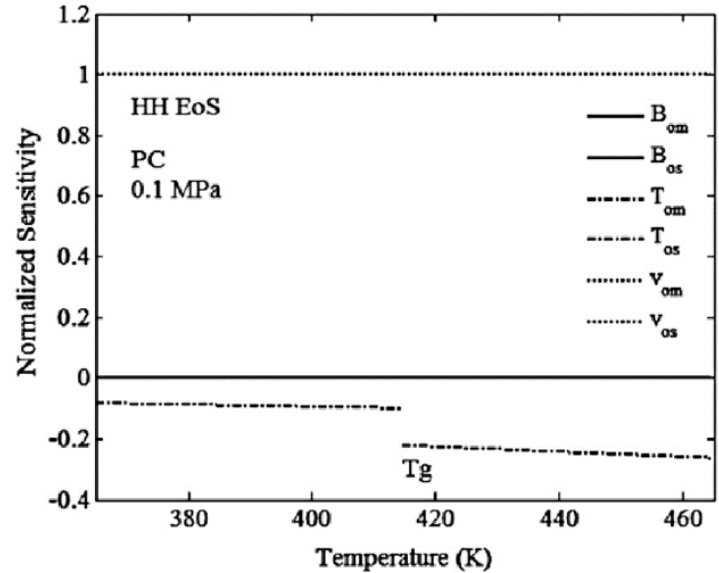

(a)

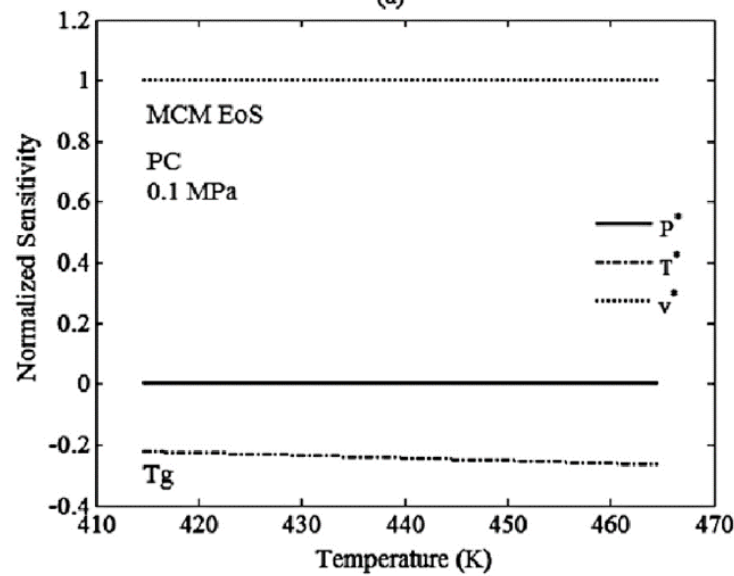

(c)

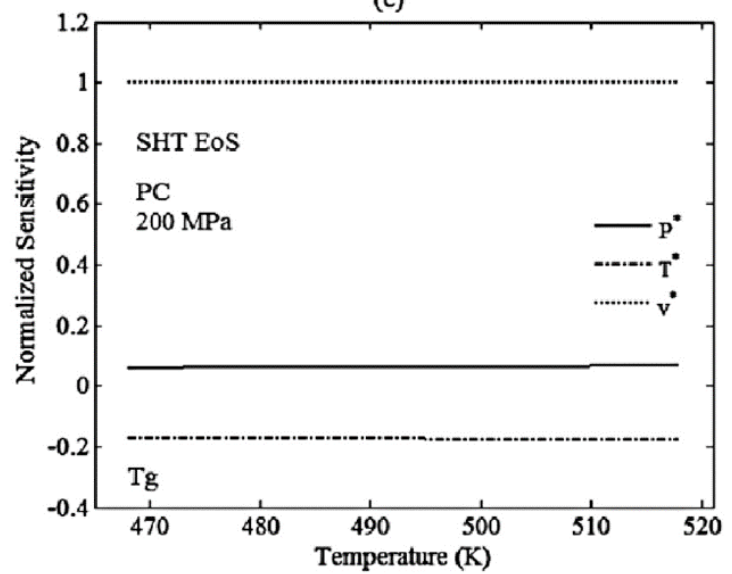

(e)

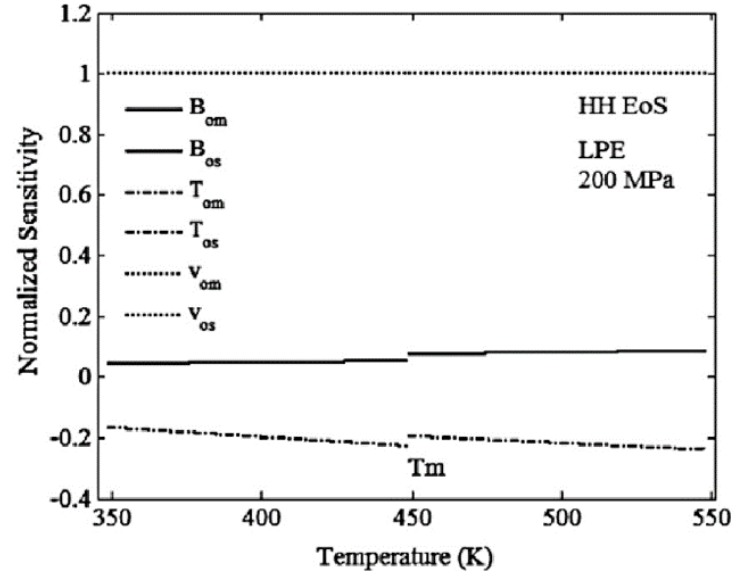

(b)

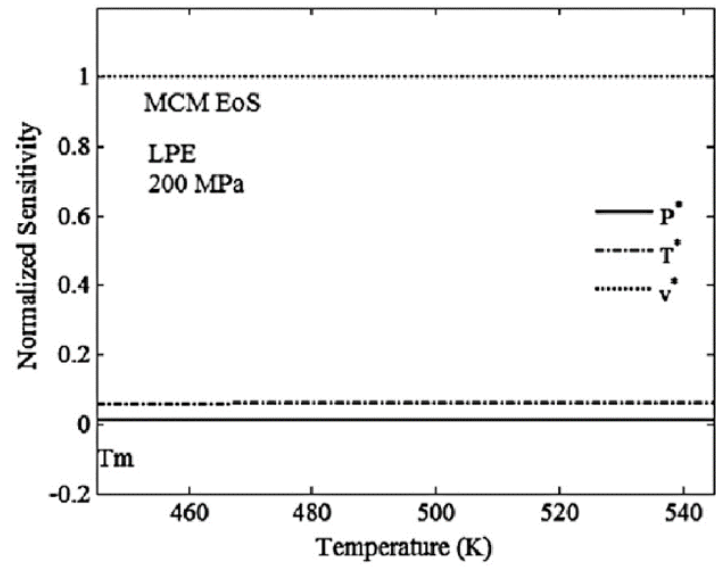

(d)

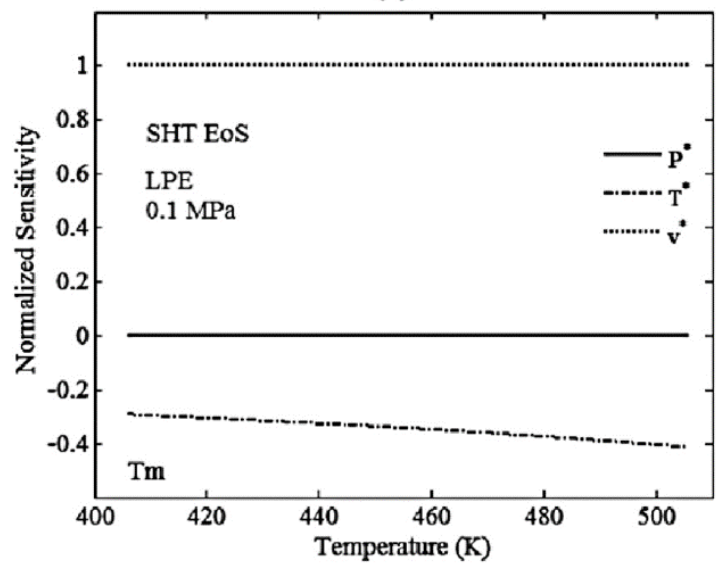

(f)

Figure 3. Normalized sensitivity of specific volume relative to the parameters of: (a) HH EoS to PC in $0.1 \mathrm{MPa}$, (b) HH EoS to LPE in $200 \mathrm{MPa}$, (c) MCM EoS to PC in $0.1 \mathrm{MPa}$, (d) MCM EoS to LPE in $200 \mathrm{MPa}$, (e) SHT EoS to PC in $200 \mathrm{MPa}$ and (f) SHT EoS to LPE in $0.1 \mathrm{MPa}$. 


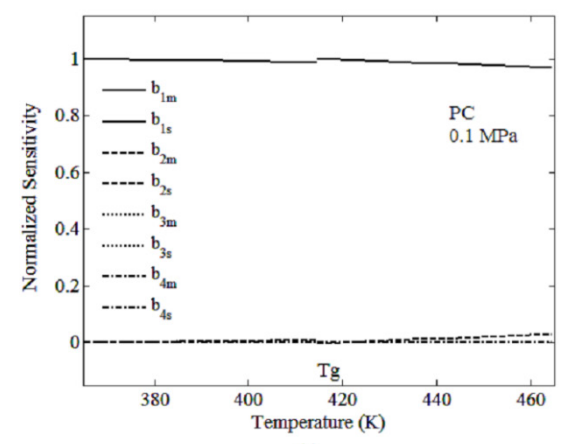

(a)

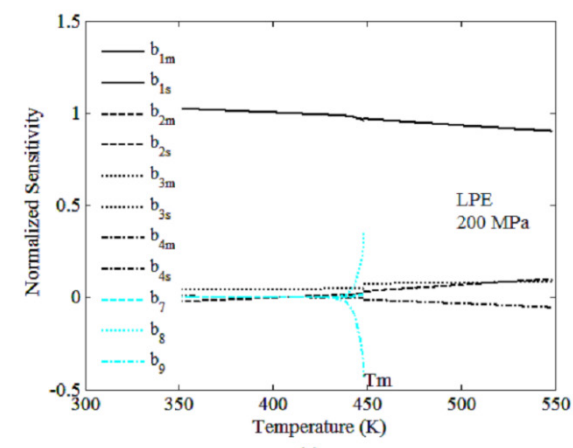

(c)

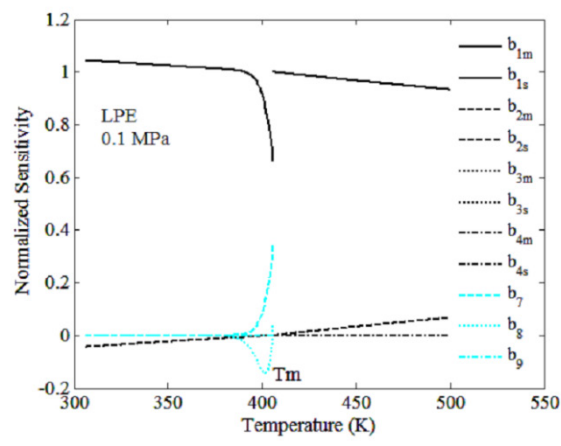

(b)

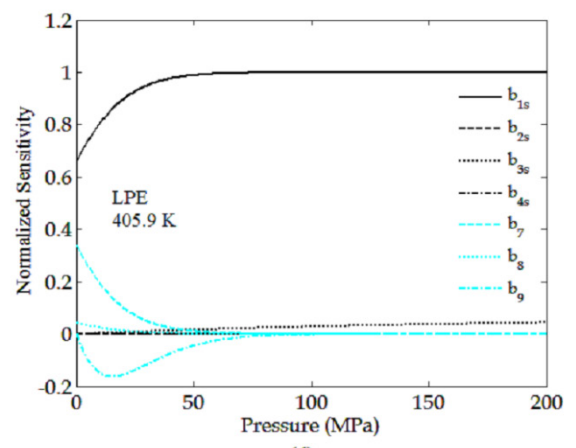

(d)

Figure 4. Normalized sensitivity of specific volume of polymers relative to parameters of Tait equation of state: (a) PC in $0.1 \mathrm{MPa}$, (b) LPE in $0.1 \mathrm{MPa}$, (c) LPE in $200 \mathrm{MPa}$ and (d) LPE in $405.9 \mathrm{~K}$.

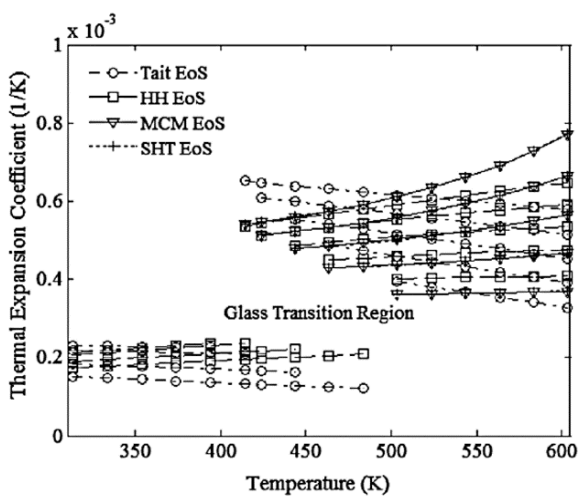

(a)

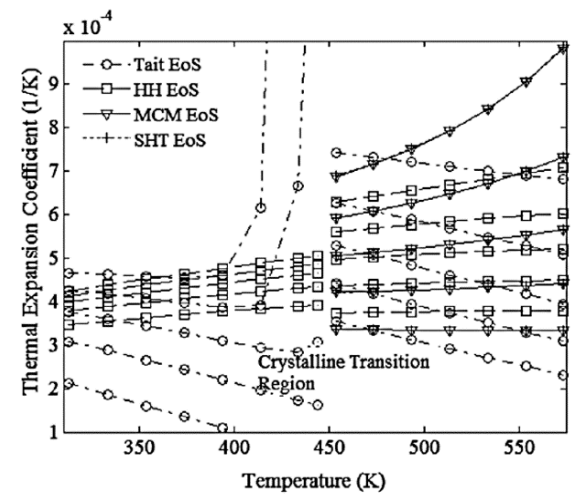

(c)

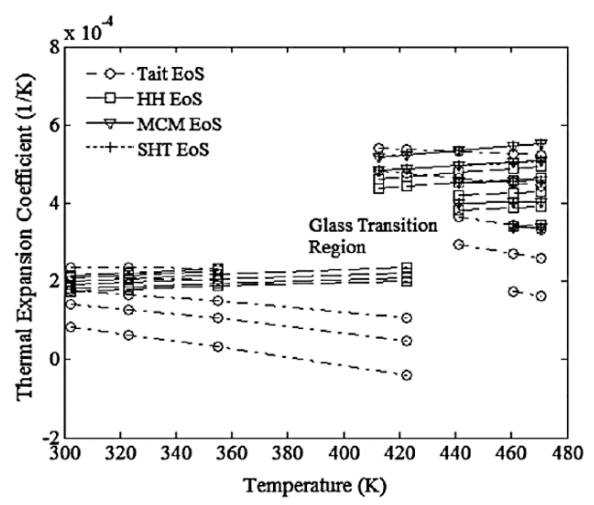

(b)

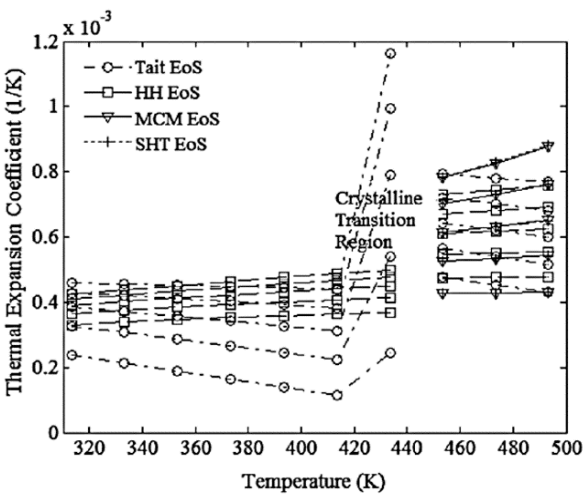

(d)

Figure 5. Isobaric thermal expansion coefficient predicted by EoS: (a) PC, (b) PoMS, (c) iPP and (d) PLA. 


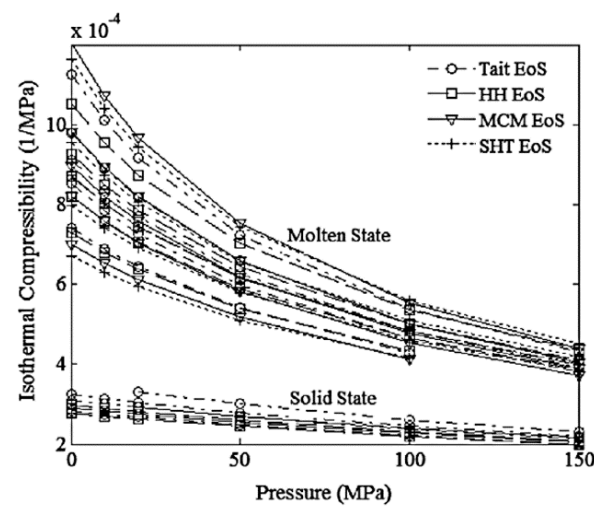

(a)

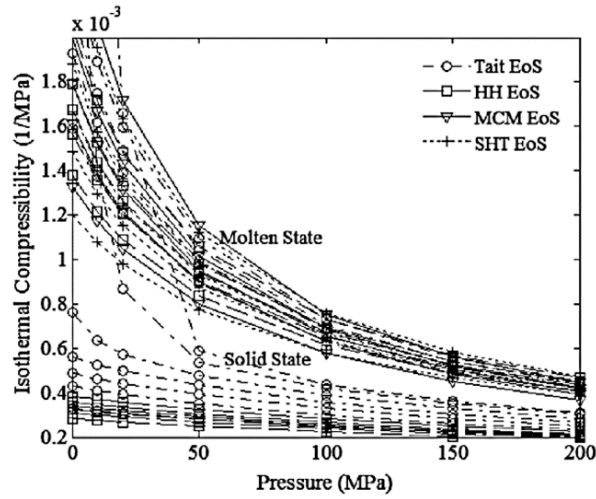

(c)

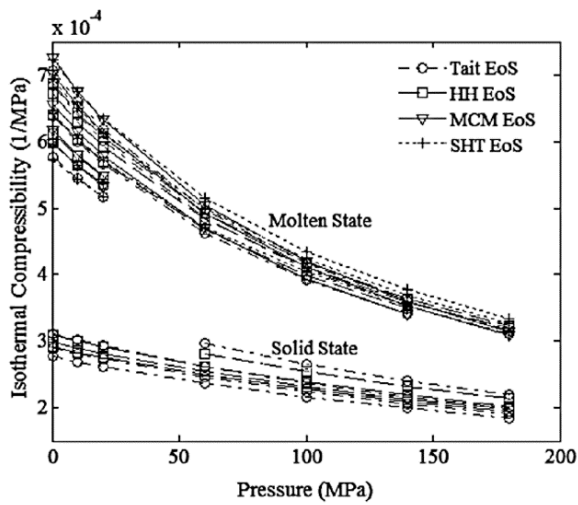

(b)

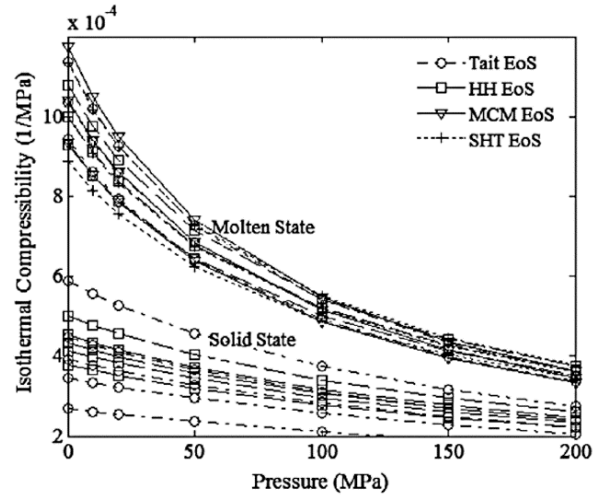

(d)

Figure 6. Isothermal compressibility predicted by EoS: (a) PC, (b) PoMS, (c) iPP and (d) PLA.

\section{Conclusions}

The Tait, HH, MCM and SHT equations of state were evaluated in prediction the PvT behavior of polymers, for both molten and solid physical states.

In the analysis of the PvT behavior of melt polymers, all equations of state studied showed adequate fitting of specific volume data, with light advantage of the Tait equation. No significant differences among them were observed in terms of quality of the estimated parameters, sensitivity of the predictions to the parameters, and of prediction of the thermal expansion and compression coefficients. Then, all EoS studied are appropriate in modeling the molten state.

In the analysis of the PvT behavior of solid polymers, Tait and $\mathrm{HH}$ equations exhibited differences in sensitivity analysis and specific volume prediction, justified mainly because HH EoS does not describe correctly the crystalline transition. The parameter estimation in both equations was adequate, with low values of standard deviations. Thus, the Tait equation of state is the most appropriate for modeling solid polymers, except for the prediction of the isobaric thermal expansion coefficient, property for which the values predicted with this equation are not in qualitative agreement with theoretical expectations.

Based on these results, the Tait equation of state can be indicated as the most appropriate for modeling the PvT behavior during processing of polymers.

\section{References}

1. Zoller, P. (1989). PVT relationships and equations of state of polymers. In J. Brandrup \& E. H. Immergut (Eds.), Polymer handbook (pp. 475-483). New York: John Wiley \& Sons.

2. Dee, G. T., \& Walsh, D. J. (1988). A modified cell model equation of state for polymer liquids. Macromolecules, 21(3), 815-817. http://dx.doi.org/10.1021/ma00181a044.

3. Rodgers, P. A. (1993). Pressure-volume-temperature relationships for polymeric liquids: A review of equations of state and their characteristic parameters for 56 polymers. Journal of Applied Polymer Science, 48(6), 1061-1080. http://dx.doi.org/10.1002/ app.1993.070480613.

4. Sy-Siong-Kiao, R. (1995). Models for the prediction of the pressure-volume-temperature relationship and the diffusion coefficient in polymer melts (Doctoral thesis). Purdue University, West Lafayette.

5. Wang, W., Liu, X., Zhong, C., Twu, C. H., \& Coon, J. E. (1997). Simplified hole theory equation of state for liquid polymers and solvents and their solutions. Industrial \& Engineering Chemistry Research, 36(6), 2390-2398. http:// dx.doi.org/10.1021/ie9604132.

6. Chiew, Y. C., Ting, S. K. H., \& Leong, K. K. (2000). A perturbed Lennard-Jones chain equation of state for polymer liquids. Fluid Phase Equilibria, 168(1), 19-29. http://dx.doi. org/10.1016/S0378-3812(99)00329-5.

7. Sato, Y., Hashiguchi, H., Inohara, K., Takishima, S., \& Masuoka, H. (2007). PVT properties of polyethylene copolymer melts. Fluid Phase Equilibria, 257(2), 124-130. http://dx.doi. org/10.1016/j.fluid.2007.01.013. 
8. Sanchez, I. C., \& Lacombe, R. H. (1976). An elementary molecular theory of classical fluids. Pure fluids. Journal of Physical Chemistry, 80(21), 2352-2362. http://dx.doi. org/10.1021/j100562a008.

9. Sanchez, I. C., \& Lacombe, R. H. (1978). Statistical thermodynamics of polymer solutions. Macromolecules, 11(6), 1145-1156. http://dx.doi.org/10.1021/ma60066a017.

10. Hartmann, B., \& Haque, M. A. (1985). Equation of state for polymer solids. Journal of Applied Physics, 58(8), 2831-2836. http://dx.doi.org/10.1063/1.335881.

11. Ougizawa, T., Dee, G. T., \& Walsh, D. J. (1989). PVT properties and equations of state of polystyrene: molecular weight dependence of the characteristic parameters in equationof-state theories. Polymer, 30(9), 1675-1679. http://dx.doi. org/10.1016/0032-3861(89)90329-7.

12. Huang, S. H., \& Radosz, M. (1990). Equation of state for small, large, polydisperse, and associating molecules. Industrial \& Engineering Chemistry Research, 29(11), 2284-2294. http:// dx.doi.org/10.1021/ie00107a014.

13. Ougizawa, T., Dee, G. T., \& Walsh, D. J. (1991). Pressurevolume-temperature properties and equations of state in polymer blends: characteristic parameters in polystyrene/ poly(vinyl methyl ether) mixtures. Macromolecules, 24(13), 3834-3837. http://dx.doi.org/10.1021/ma00013a015.

14. Song, Y., Lambert, S. M., \& Prausnitz, J. M. (1994). A perturbed hard-sphere-chain equation of state for normal fluids and polymers. Industrial \& Engineering Chemistry Research, 33(4), 1047-1057. http://dx.doi.org/10.1021/ie00028a037.

15. Sanchez, I. C., \& Cho, J. (1995). A universal equation of state for polymer liquids. Polymer, 36(15), 2929-2939. http://dx.doi. org/10.1016/0032-3861(95)94342-Q.

16. Jeon, K. S., Char, K., Walsh, D. J., \& Kim, E. (2000). Thermodynamics of mixing estimated by equation-ofstate parameters in miscible blends of polystyrene and tetramethylbisphenol-A polycarbonate. Polymer, 41(8), 28392845. http://dx.doi.org/10.1016/S0032-3861(99)00350-X.

17. Gross, J., \& Sadowski, G. (2001). Perturbed-chain SAFT: an equation of state based on a perturbation theory for chain molecules. Industrial \& Engineering Chemistry Research, 40(4), 1244-1260. http://dx.doi.org/10.1021/ie0003887.

18. Broza, G., Castaño, V. M., Martinez-Barrera, G., Menard, K. P., \& Simões, K. P. (2005). P-V-T properties of a polymer liquid crystal subjected to pre-drawing at several temperatures. Physica B: Condensed Matter, 357(3-4), 500-506. http:// dx.doi.org/10.1016/j.physb.2004.12.018.

19. Wang, M., Takishima, S., Sato, Y., \& Masuoka, H. (2006). Modification of Simha-Somcynsky equation of state for small and large molecules. Fluid Phase Equilibria, 242(1), 10-18. http://dx.doi.org/10.1016/j.fluid.2006.01.003.

20. Simha, R., \& Utracki, L. A. (2010). PVT properties of linear and dendritic polymers. Journal of Polymer Science: Part B, Polymer Physics, 48(3), 322-332. http://dx.doi.org/10.1002/ polb.21893.

21. Winterbone, D. E. (1997). Advanced thermodynamics for engineers. London: Arnold.

22. Utracki, L. A. (2009). Compressibility and thermal expansion coefficients of nanocomposites with amorphous and crystalline polymer matrix. European Polymer Journal, 45(7), 1891-1903. http://dx.doi.org/10.1016/j.eurpolymj.2009.04.009.
23. Utracki, L. A. (2010). PVT of amorphous and crystalline polymers and their nanocomposites. Polymer Degradation \& Stability, 95(3), 411-421. http://dx.doi.org/10.1016/j. polymdegradstab.2009.07.020.

24. Chang, R. Y., Chen, C. H., \& Su, K. S. (1996). Modifying the tait equation with cooling-rate effects to predict the pressurevolume-temperature behaviors of amorphous polymers: modeling and experiments. Polymer Engineering and Science, 36(13), 1789-1795. http://dx.doi.org/10.1002/pen.10574.

25. Prigogine, I., Trappeniers, N., \& Mathot, V. (1953). Statistical thermodynamics of r-MERS and r-MER solutions. Discussions of the Faraday Society, 15, 93-107. http://dx.doi.org/10.1039/ df9531500093.

26. Simha, R., \& Somcynsky, T. (1969). On the statistical thermodynamics of spherical and chain molecule fluids. Macromolecules, 2(4), 342-350. http://dx.doi.org/10.1021/ ma60010a005.

27. Zhong, C., Wang, W., \& Lu, H. (1993). Simplified hole theory equation of state for polymer liquids. Fluid Phase Equilibria, 86(1), 137-146. http://dx.doi.org/10.1016/0378-3812(93)87172-W.

28. Utracki, L. A. (2007). Pressure-volume-temperature of molten and glassy polymers. Journal of Polymer Science: Part B, Polymer Physics, 45(3), 270-285. http://dx.doi.org/10.1002/ polb.21031.

29. Sato, Y., Yoshiteru, Y., Takishima, S., \& Masuoka, H. (1997). Precise measurement of the PVT of polypropylene and polycarbonate up to $330^{\circ} \mathrm{C}$ and $200 \mathrm{MPa}$. Journal of Applied Polymer Science, 66(1), 141-150. http://dx.doi.org/10.1002/ (SICI)1097-4628(19971003)66:1<141::AID-APP17>3.0.CO;2-4.

30. Olabisi, O., \& Simha, R. (1975). Pressure-volume-temperature studies of amorphous and crystallizable polymers. I. Experimental. Macromolecules, 8(2), 206-210. http://dx.doi.org/10.1021/ ma60044a022.

31. Quach, A., \& Simha, R. (1971). Pressure-volume-temperature properties and transitions of amorphous polymers; polystyrene and poly (orthomethylstyrene). Journal of Applied Physics, 42(12), 4592-4606. http://dx.doi.org/10.1063/1.1659828.

32. Sato, Y., Inohara, K., Takishima, S., Masuoka, H., Imaizumi, M., Yamamoto, H., \& Takasugi, M. (2000). Pressure-volumetemperature behavior of polylactide, poly(butylene succinate), and poly(butylene succinate-co-adipate). Polymer Engineering and Science, 40(12), 2602-2609. http://dx.doi.org/10.1002/ pen. 11390 .

33. Wang, J., Xie, P., Yang, W., \& Ding, Y. (2010). Online pressurevolume-temperature measurements of polypropylene using a testing mold to simulate the injection-molding process. Journal of Applied Polymer Science, 118(1), 200-208. http://dx.doi. org/10.1002/app.32070.

34. Himmelblau, D. M. (1970). Process analysis by statistical. New York: John Wiley \& Sons.

35. van Krevelen, D. W., \& te Nijenhuis, K. (2009). Properties of polymers. Amsterdam: Elsevier Science.

36. van der Vegt, A. K. (2002). From polymers to plastics. Delft: DUP Blue Print.

Received: Feb. 01, 2014

Revised: Oct. 22, 2014

Accepted: Dec. 04, 2014 